\title{
Ouroboros: Um jogo de tabuleiro para o Ensino de Química
}

\author{
OuroBoros: A board game board for chemical teaching
}

\begin{abstract}
Aline Balbueno Freitas (alinebalbuenofreitas@gmail.com)
Grupo Interdisciplinar em Pesquisa em Prática de Ensino - GIPPE, Universidade Federal do Pampa, Campus Uruguaiana, Uruguaiana, RS, CEP: 97500-970

Daisy de Lima Nunes (d_lima_n@ $@$ hotmail.com)

Grupo Interdisciplinar em Pesquisa em Prática de Ensino - GIPPE, Universidade Federal do Pampa, Campus Uruguaiana, Uruguaiana, RS, CEP: 97500-970

Carla Cristina Borges Medina (carlab_m@ hotmail.com)

Grupo Interdisciplinar em Pesquisa em Prática de Ensino - GIPPE, Universidade Federal do Pampa, Campus Uruguaiana, Uruguaiana, RS, CEP: $97500-970$
\end{abstract}

Maria Laura Videiro Schmitt (marialauravschmitt@gmail.com)

Grupo Interdisciplinar em Pesquisa em Prática de Ensino - GIPPE, Universidade Federal do Pampa, Campus Uruguaiana, Uruguaiana, RS, CEP: 97500-970

Maiara Dias Büttenbender (mairadbuttenbender@gmail.com)

Grupo Interdisciplinar em Pesquisa em Prática de Ensino - GIPPE, Universidade Federal do Pampa, Campus Uruguaiana, Uruguaiana, RS, CEP: 97500-970

Amanda Gomes de Abreu (amandaabreu1999@outlook.com)

Grupo Interdisciplinar em Pesquisa em Prática de Ensino - GIPPE, Universidade Federal do Pampa, Campus Uruguaiana, Uruguaiana, RS, CEP: $97500-970$

Mário Sérgio Nunes Bica (mario_soad@msn.com)

Grupo Interdisciplinar em Pesquisa em Prática de Ensino - GIPPE, Universidade Federal do Pampa, Campus Uruguaiana, Uruguaiana, RS, CEP: 97500-970

Rafael Roehrs (rafaelroehrs@ unipampa.edu.br)

Grupo Interdisciplinar em Pesquisa em Prática de Ensino - GIPPE, Universidade Federal do Pampa, Campus Uruguaiana, Uruguaiana, RS, CEP: 97500-970

Resumo: Os jogos de tabuleiros são uma ferramenta de aprendizagem significativa no ensino de Química. O jogo de tabuleiro Ouroboros, criado no GIPPE (Grupo interdisciplinar em pesquisa em prática de ensino), tem como objetivo geral enfatizar a importância de proporcionar condições para o aluno aprender química de forma lúdica, jogando. Foi realizado um teste com os alunos da Graduação de Ciências da Natureza, a fim de verificar o rendimento da turma. Aplicou-se a metodologia de campo para posteriormente comprovar-se essa dinâmica por meio da pesquisa bibliográfica. Os jogos são instrumentos cada vez mais eficazes na construção do conhecimento, dentre eles, OuroBoros pode ser tanto um jogo didático, como também instrumento para

Recebido em: 24/03/2020

Aceito em: 20/07/2020 
auxiliar na aprendizagem e ainda despertar a interação social do aluno. O objetivo desse trabalho foi avaliar o jogo como um recurso pedagógico que viabiliza, além da ludicidade, o conhecimento do conteúdo da ementa no processo de ensinoaprendizagem em uma turma de Graduação de Licenciatura de Ciências da Natureza.

Palavras-chave: jogo didático-OuroBoros-alunos-aprendizagem-química

Abstract: Board games are a significant learning tool in teaching chemistry. The "Ouroboros" board game created in "GIPPE" (Interdisciplinary Group of Researching in Teaching Practice) has the general objective to emphasize the importance of providing conditions for the students to learn chemistry by playing. A test with Natural Sciences Undergraduation students was carried out to verify the class performance. A field research methodology was applied to prove its dynamic throughout bibliographic already known in the literature, meaning that games are increasingly effective tools in construction of knowledge, in other words, "Ouroboros" might be a didactic game and instrument that could help in the learning process and still arouse students social interaction. The main objective of this article was to evaluate the game as a pedagogical resource that makes possible, besides the playfulness, the knowledge of the content in the teaching-learning process in a class of Undergraduate Degree in Natural Sciences.

Keywords: didactic game-Ouroboros-students-learning-chemistry

\section{INTRODUÇÃO}

Atualmente é necessário que o estudante e o professor reaprendam a brincar independente de sua idade. Existem jogos para todas as faixas etárias, considerando-se adolescentes e adultos que buscam por jogos com objetivos já pré-estipulados, usados como atividade de lazer, e crianças que se divertem com jogos de montar, pelo ato de brincar (SOARES, 2015). Nesta perspectiva, o professor deve rever suas metodologias de ensino, de modo que o lúdico seja inserido em seus planejamentos como uma ferramenta didática, que incentiva o aluno a querer aprender de forma prazerosa, melhorando a interação do grupo de alunos (MEDEIROS; RODRIGUES; SILVEIRA, 2016).

A utilização de atividades lúdicas, como jogos didáticos por acadêmicos de licenciatura na universidade, auxilia no seu ensino-aprendizagem. Esta metodologia também estimula os futuros docentes a repensarem em suas práticas pedagógicas, sendo que os jogos didáticos se apresentam como ferramentas metodológicas que podem e devem ser incluídas nos planejamentos de aula de química do Ensino Médio e de ciências do Ensino Fundamental Anos Finais (SILVA et all., 2017). O uso de jogos didáticos em sala de aula estimula e incentiva os alunos a aprender, através de uma

Recebido em: 24/03/2020

Aceito em: 20/07/2020 
metodologia que complementa as aulas expositivas dialogadas, evidenciando um aluno ativo na construção do saber (REZENDE et all., 2018).

Os jogos no ensino de química englobam a importância de mostrar que o processo de ensino não precisa ser penoso e regulador. Abrem a possibilidade do aluno aprender sem a necessidade de memorizar e escrever repetidas vezes o conteúdo para seu efetivo entendimento e, dessa forma, tornam a escola um espaço privilegiado para a construção do conhecimento de forma descontraída. Para Almeida (2009), se o professor conseguir conciliar na sala de aula os objetivos pedagógicos com a vontade dos alunos, pode transformar o espaço em brincadeira.

Um jogo pode ser considerado educativo quando mantém um equilíbrio entre duas funções: a lúdica e a educativa. Segundo Kishimoto (1996), o lúdico está relacionado ao caráter de diversão e prazer que um jogo propicia. Enquanto, a função educativa se refere à apreensão de conhecimentos, habilidades e saberes. Deus e Soares (2020) se referem ao jogo educativo ou jogo pedagógico como aquela atividade que é utilizada em sala de aula de forma tradicional para o ensino.

O jogo OuroBoros procura contemplar essas duas funções, tanto em termos de características e ações lúdicas, ou seja, atividades lúdicas que implicam em prazer, em divertimento, na liberdade e na voluntariedade que contenham um sistema de regras claras e explícitas e que tenham um lugar delimitado onde possam agir: um espaço ou um brinquedo. Já em características educativas, o jogo relaciona a aprendizagem de conceitos, não sendo uma atividade totalmente livre e descomprometida, mas uma atividade intencional, através da mediação e orientação do professor.

A importância da inserção desta forma de atividade pedagógica justifica-se pela necessidade do professor em diversificar as metodologias de ensino, visando que nos dias atuais a educação está buscando alunos ativos, instigantes e argumentativos (TEIXEIRA, DOS SANTOS; GRAEBNER, 2019). O uso do jogo didático apresenta essas características, por ser uma atividade divertida e educativa ao mesmo tempo, modificando a sua percepção dos discentes de ensino, de modo que, reflete positivamente no processo de ensino-aprendizagem (SILVA et all., 2019).

O interesse pela temática desse trabalho surgiu pela importância de mostrar que o processo de ensino, na escola, não precisa ser penoso e regulador, e que os alunos podem aprender sem que seja necessário, somente, memorizar e escrever repetidas vezes para que consigam compreender o conteúdo. Desta forma, a escola pode ser 
relacionada a um espaço privilegiado para a construção do conhecimento de forma descontraída. Atualmente vem crescendo a utilização de jogos como ferramenta didática dentro da sala de aula. A utilização de um jogo com característica didática se dá por ele abranger o conteúdo específico da aula, de modo que seu uso seja feito com o objetivo de uma aprendizagem significativa mediada pelo professor (ESCREMIN; CALEF, 2018). O professor, ao planejar seu uso, visa que o jogo substitua uma lista de exercícios, uma aula de revisão de conteúdo.

O processo de ensino e aprendizagem não precisa se tornar uma tortura para o futuro professor, ele precisa de uma boa formação pedagógica pela Universidade e agregar o conhecimento às boas experiências, para aplicá-las, futuramente, em suas aulas. Os acadêmicos muitas vezes se preocupam mais com o conhecimento específico, deixando de lado o conhecimento pedagógico pela falta de entrosamento das disciplinas específicas e pedagógicas na universidade, apresentando dificuldades na rotina como docente, no futuro profissional (CORRÊA; SCHNETZLER, 2017). Assim, a utilização de uma metodologia lúdica, utilizando um jogo de tabuleiro, torna possível desenvolver o conteúdo utilizando os requisitos supracitados que ajudarão os estudantes a aprender de uma forma mais positiva, ou seja, descontraída e prazerosa (SANTOS, 2018).

A aquisição do conhecimento é um dos benefícios que o jogo didático pode proporcionar, pois sua aplicação motiva os alunos (ESCREMIN; CALEF, 2018). O graduando deve ter consciência de que essa metodologia pode e/ou deve ser inserida em qualquer campo de ação da prática pedagógica desde que seja planejada, lembrando também que poderá ser utilizada quando iniciar o seu trabalho profissional como docente (MEDEIROS; RODRIGUEZ; SILVEIRA, 2016).

Os discentes em Licenciaturas em Ciências da Natureza devem se conscientizar de que existe uma dicotomia: de um lado governam as características do ensino tradicional escolar, na qual apenas os conteúdos programáticos são depositados como saberes a cada discente; no qual primeiramente cada aluno deveria decorá-lo e reproduzir de acordo com algumas disciplinas em ementas estagnes tendo como consequências conteúdos descontextualizados (ROCHA; VASCONCELOS, 2016). Não desvalorizando as aulas tradicionais, elas são importantes desde que sejam expositivas e dialogadas, tendo o aluno como ativo na sua construção do saber (HARTMANN; MARONN; SANTOS, 2019). E do outro lado, existe atualmente a possibilidade de aplicar-se os jogos didáticos, como o OuroBoros, uma ferramenta lúdica para despertar 
o interesse do aluno, objetivando um aprendizado significativo nas aulas de química (SOARES, 2015).

Essa proposta pedagógica lúdica: “OuroBoros: Um jogo de tabuleiro para o ensino de Química" tem como objetivo geral valorizar a importância de metodologias lúdicas, através de atividades onde o jogo atua como instrumento viável de aprendizagem na sala de aula.

\section{A ORIGEM DOS JOGOS DIDÁTICOS}

É muito difícil encontrar uma literatura acerca da origem dos jogos didáticos, mas sabe-se que o primeiro artigo publicado foi em 1935, e depois disso houve um longo período sem se falar nesta metodologia lúdica de ensino, voltando a ter publicações a partir de 1970 (LAPA; SILVA, 2018).

Uma das vantagens do uso dos jogos didáticos como atividades de ensino é que por serem atividades lúdicas, facilitam a aprendizagem por sua própria acepção, pois os mecanismos para os processos de descoberta e o empenho para isso são intensificados.

Assim, considerando o jogo didático como uma atividade diferenciada, constituída por regras, orientada pelo professor, que mantém um equilíbrio entre a função educativa e a função lúdica, podemos dizer que esses jogos podem ser utilizados como recurso didático de várias formas, dependendo, inicialmente, da característica do jogo e, posteriormente, do planejamento didático do professor (CUNHA, 2012, p. 95).

Para Melo (2005) vários estudos a respeito de atividades lúdicas vêm comprovar que o jogo, além de ser fonte de prazer e descoberta para o aluno, é a tradução do contexto sociocultural e histórico refletido na cultura, podendo contribuir para o processo de construção do conhecimento do futuro educador, como mediadores da aprendizagem. Acreditando que um jogo didático contribui positivamente dentro do ambiente escolar, ao auxiliar na construção e reconstrução do conhecimento pelos alunos como jogadores, e o professor tem a função de mediar o conhecimento, não dar as repostas, mas induzir seus alunos a reflexão e formação do pensamento crítico do conteúdo.

Por outro lado, há a instituição que impõe ao estudante muitas vezes uma atitude de passividade, tanto em função dos métodos adotados quanto da configuração física dos espaços e das condições de aprendizado tradicional. Por isso, visando substituir esse 
estereótipo é que se propõe o jogo Ouroboros como uma nova maneira de aprender com mais facilidade e menos imposição (PEREIRA, 2017).

\section{O JOGO OUROBOROS:}

Ouroboros é uma figura da mitologia grega onde oura significa cauda e boros significa comer ou devorar, pode ser representado por uma serpente, cobra ou dragão que engole sua própria cauda. E simboliza o ciclo da vida, a eternidade, o tempo, a evolução, a fecundação, o nascimento, a morte, a ressurreição, a mudança, a criação, a destruição, a renovação e muitas vezes o Ouroboros é relacionado ao universo (ADVERSE, 2019; SOUSA, 2012).

Com isso, um jogo criado e construído no Grupo interdisciplinar em pesquisa em prática de ensino (GIPPE) é constituído por um tabuleiro e 54 cartas com perguntas sobre química geral, e permite a possibilidade da participação de vários jogadores simultaneamente. O conteúdo escolhido para esse momento foi átomos e moléculas, substâncias químicas e suas interações, e reações químicas. Os referidos temas foram escolhidos por estarem dentro do conteúdo programático da disciplina onde foi utilizado o recurso, mas o tabuleiro do Ouroboros foi construído para se adaptar a qualquer conteúdo de química. Os alunos devem ser divididos em jogadores ou grupos de jogadores. Após se determinar quem inicia, é preciso jogar os dados, antes de colocar sua peça no lugar correspondente ao número que saiu nos dados. Cada participante ou o grupo deve escolher um número de um a cinquenta e quatro das questões, isto é, se responderem corretamente, sua peça será colocada no lugar indicado e a jogada agora pertencerá ao outro jogador.

No tabuleiro existem algumas figuras que indicam outras regras importantes, tais como: se a peça cair em um Béquer é preciso voltar duas casas, também têm símbolos indicando o que fazer, se a peça cair no símbolo da radiação é preciso voltar algumas casas. Há também o desenho de uma estrela onde o grupo deve responder duas perguntas, se acertar, acontecerá uma mudança de nível, caso contrário voltará duas casas. O grupo vencedor é aquele que terminar o percurso primeiro.

O uso de jogos didáticos de tabuleiro estimula os jogadores favorecendo a troca de conhecimento através de discussões e argumentações, gerando a reconstrução do saber e, também gera neste tipo de jogo, uma competição, por existir um ganhador e um

Recebido em: 24/03/2020

Aceito em: 20/07/2020 
perdedor (SOARES, 2015). Proporciona uma motivação do saber, um melhor entrosamento entre os jogadores, incentivando os alunos a aprender química desenvolvendo habilidades e competências menos exploradas em aulas expositivas dialogadas (ESCREMIN; CALEF, 2018).

Como objetivos específicos temos: identificar se o jogo Ouroboros proporcionou momentos lúdicos e prazerosos ao aluno; descrever o comportamento da turma durante a aplicação do jogo; verificar a possibilidade de ser construída uma aprendizagem de maneira mais atraente e significativa.

\section{MATERIAIS E MÉTODOS UTILIZADOS}

Considerando-se que o saber não é adquirido do nada, e que aprendizagem é uma reconstrução de saberes prévios. O público-alvo desta pesquisa foi uma turma de graduação de Licenciatura em Ciências da Natureza do IV semestre que possuía cinquenta e seis alunos. Após a aula que abordava o conteúdo de átomos e moléculas, substâncias químicas e suas interações, e reações químicas foi aplicado um pré-teste, com dez questões, com seis questões de múltipla escolha e quatro questões discursivas.

As perguntas eram relacionadas aos seguintes conceitos: átomos e moléculas, substâncias químicas, suas interações e reações químicas, como ilustra a figura 1. Consequentemente, para atingir tal finalidade foi necessário utilizarem-se os seguintes materiais: uma avaliação prévia individual (pré-teste) com dez questões; um tabuleiro por grupo de quatro pessoas, dois dados por tabuleiro, personagens de chumbo utilizados em jogos de RPG (Role-Playing Game) para representar os grupos; uma folha com 54 questões de química.

Inicialmente os alunos responderam uma avaliação individual (pré-teste) com dez questões. Para a execução da atividade os alunos foram divididos em 10 grupos de cinco a seis jogadores. Cada grupo recebeu um tabuleiro (figura 2), dois dados e dois personagens. Foram explicadas as regras de forma clara e objetiva, e as respostas das cartas ficaram com os mediadores da atividade (dois alunos da graduação de Ciências da Natureza e o professor regente da classe). Para iniciar, cada equipe jogava os dados e começava aquela que tirasse a maior pontuação. Os jogadores rolavam os dados para poder andar pelo percurso do tabuleiro. Caso o personagem parasse em cima de uma posição com alguma figura, era consultado o tabuleiro (figura 2), para verificar a ação 


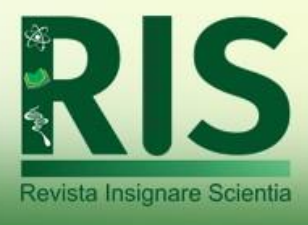

Vol. 3, n. 5. Set./Dez.

ISSN: 2595- 4520

aplicada. Venceria a equipe que terminasse primeiro o percurso ou fizesse o maior percurso no tempo destinado pelo professor.

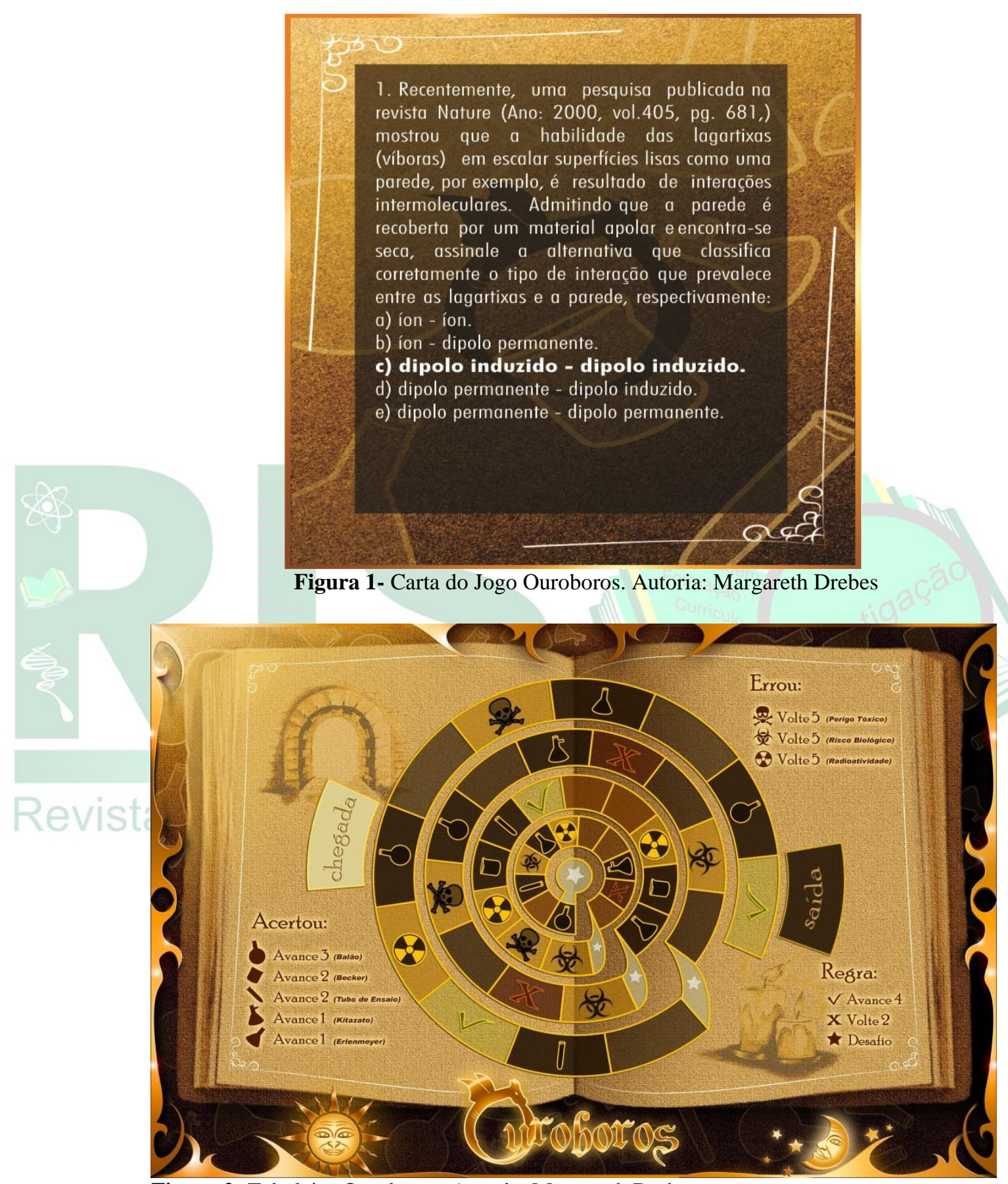

Figura 2- Tabuleiro Ouroboros. Autoria: Margareth Drebes

Todas as perguntas do baralho de cartas do jogo abrangiam o conteúdo que os jogadores já apresentavam conhecimento, e os mesmos foram orientados a chamar os mediadores em caso de dúvidas nas respostas. Após o jogo, na aula subsequente, aplicou-se um teste individual para avaliar o pós-jogo. O teste apresentava dez questões, repetindo algumas questões do pré-teste (as que obtiveram maior número de erros) e Recebido em: 24/03/2020 Aceito em: 20/07/2020 
questões novas. De modo que o resultado do pós-jogo avaliasse se houve melhora dos alunos na assimilação do conteúdo de química.

\section{RESULTADOS E DISCUSSÕES}

Diante da perspectiva de esperar por respostas às indagações, esse trabalho propôs aplicar o jogo na sala de aula a fim de buscar respostas comportamentais e intelectuais sobre o impacto da atividade lúdica no ensino de química. Através do conteúdo já estudado por esta turma, avaliar a relevância de trabalhar com jogos na sala de aula, primeiramente nas turmas de graduação e posteriormente no Ensino Fundamental Anos Finais e no Ensino Médio.

Tendo como uma das intenções propiciar condições de completar a formação geral do estudante numa ação articulada e de maneira contextualizada, ou seja, onde os conhecimentos da química possam apresentar sentido a todos os alunos em sua aplicação no cotidiano. Pois, como futuros docentes de Ciências da Natureza, devem buscar metodologias e estratégias que incentivem seus alunos a se aproximar do conteúdo de química, diminuindo a distância do seu conhecimento com o seu cotidiano (MEDEIROS; RODRIGUEZ; SILVEIRA, 2016).

Constata-se que num mundo como o da atualidade, de tão rápidas transformações científicas e tecnológicas, e de tantas contradições, estar formado para a vida significa mais do que repetir informações, o graduando deve denominar classificações ou identificar símbolos. Como futuro professor deve pesquisar em livros e artigos metodologias e estratégias de jogos, com o propósito de adaptar para suas turmas diversificando a sua práxis e objetivando um aprendizado significativo (SOARES, 2015). Nesse sentido, o jogo educativo ou pedagógico apresenta-se como uma das alternativas dentro das metodologias de ensino para motivar nos alunos, o seu interesse e curiosidade pelo componente curricular de química e a alfabetização científica dentro da área de Ciências da Natureza (BENEDETTI FILHO et. al, 2020)

Significa que o discente precisa saber se informar, comunicar, argumentar, compreender e agir; enfrentar problemas de diferentes naturezas; participar socialmente, de forma prática e solidária; ser capaz de elaborar críticas ou propostas e, especialmente, adquirir uma atitude de permanente aprendizado. Ou seja, buscar por uma educação contextualizada e problematizada, envolvendo seus conteúdos com acontecimentos da atualidade, a fim de que seu aluno torne-se mais crítico e reflexivo

Recebido em: 24/03/2020

Aceito em: 20/07/2020 
perante os acontecimentos da sociedade (MEDEIROS; RODRIGUEZ; SILVEIRA, 2016).

A partir disso, a graduação determina quais seriam os métodos de aprendizado mais compatíveis, ou seja, quais seriam as condições essenciais para que os futuros docentes sejam capazes de se deparar com problemas, compreendê-los e enfrentá-los, participando de um convívio social que lhes oportunizasse realizar-se como cidadãos ativos e atuantes na sociedade. Fazendo também as escolhas e as suposições com a intenção de tomar gosto pelo conhecimento, aprender a aprender conteúdo da ementa de química e ampliar o apreço e satisfação pela emoção de ser professor (CORRÊA; SCHNETZLER, 2017).

Partindo-se desse pressuposto, Ouroboros foi desenvolvido: um jogo de tabuleiro para o ensino de Química. Através do pré-teste aplicado aos graduandos, o conteúdo/tema de menor conhecimento foi avaliado e selecionado, desta forma podendo direcionar o conteúdo das cartas do jogo. A aplicação do jogo também permitiu que os graduandos pudessem ter a oportunidade de uma prática diferenciada da metodologia comumente utilizada pela Universidade. Consequentemente, surge a necessidade do futuro profissional do ensino de Ciências da Natureza saber se realmente deve pontuar o jogo como um recurso de aprendizagem, como uma ferramenta que seja capaz de gerar situações em que seus alunos discutam os conteúdos, proporcionando a troca de saberes, através da reflexão e de suas ações, possibilitando expor seus conhecimentos de forma divertida aos seus colegas (SOARES, 2015).

Além disso, observa-se que existe a necessidade de a escola mediar os conhecimentos de importância da química como uma disciplina que precisa oferecer recursos contextualizados, por possuir elementos químicos que devem estar presentes no dia a dia. A apresentação de símbolos e signos não usuais torna os alunos indiferentes à construção do conhecimento, por não relacionarem estes símbolos com a sua vivência, faltando o real sentido entre o conhecimento e sua aplicação prática (MEDEIROS; RODRIGUEZ; SILVEIRA, 2016).

Os professores são mediadores e sua tarefa consiste em ajudar os alunos a desenvolver seu conhecimento. Sua ação mediadora mais importante é de prover situações de aprendizagem frutíferas para os estudantes. A diversidade de situações em que é possível explorar a Química é incalculável e muito rica. O uso de diversas expressões permite a interiorização de muitos conceitos químicos, sem que os alunos se 
deem conta. Essas situações devem ser cuidadosamente escolhidas, ordenadas, diversificadas e apresentadas no momento certo (MOREIRA, 2009).

Para que isso aconteça de forma bem-sucedida, urge que o docente elabore estratégias metodológicas questionadoras e lúdicas para que o discente possa refletir diretamente sobre o seu processo de ensino-aprendizagem demonstrando interesse em participar ativamente da construção de sua aprendizagem (PEREIRA, 2016). Compete ao professor olhar para a sala de aula, não como um mero transmissor dos conteúdos: fórmulas, evidências de transformações químicas, sistemas gasosos, lei dos gases, equação geral dos gases ideais, misturas gasosas, modelo corpuscular da matéria, modelo atômico de Dalton, natureza elétrica da matéria, átomos e sua estrutura, número atômico, número de massa, isótopos, massa atômica, elementos químicos, tabela periódica, reações químicas; mas sim como o criador de um ambiente construtivo e de reconstrução de conhecimento para seus discentes, utilizando práticas pedagógicas inovadoras, onde os discentes sintam desejo e interesse em participar ativamente da aula (SILVA et all., 2017).

O professor deve mostrar aos discentes as inúmeras possibilidades para que esses atuem de forma reflexiva, participativa e atuante na comunidade escolar. Por este motivo, é admissível que o professor faça um trabalho grandioso quando se utiliza de ferramentas que farão com que o aluno se movimente e crie diferentes estratégias para vencer. Tudo está mudando, inclusive a educação na disciplina de química, e há vários anos tem-se dado ênfase em diversas estratégias e propostas que vem sendo analisadas e discutidas dentro de alguns pontos de vista da didática das ciências (GIZ-PEREZ, 1993; GALIAZZI et all., 2001; CAMPANARIO; MOYA, 1999). A aplicação do jogo Ouroboros levou os discentes a uma interação rápida e objetiva com os colegas do grupo, buscando a resposta correta das questões, e essa atitude vai ao encontro com o que salienta Vygotsky:

Os jogos didáticos requerem que o aluno exercite o raciocínio rápido, percepção, crie estratégias. Nessa direção, os jogos didáticos surgem como uma alternativa, pois incentivam o trabalho em equipe e a interação alunoprofessor; auxiliam no desenvolvimento de raciocínio e habilidades; e facilitam o aprendizado de conceitos (VYGOTSKY, 1989, p. 72).

Basta apenas escolher o conteúdo que irá aplicar na sala de aula e colocar as perguntas no tabuleiro para que os graduandos, ao jogar, aprendam mais sobre representação das transformações químicas: fórmulas químicas, balanceamento de 
equações químicas, aspectos quantitativos das transformações químicas, leis ponderais das reações químicas, determinação de fórmulas químicas, grandezas químicas, etc. $\mathrm{O}$ jogo trouxe em suas questões mais do que teoria e nomenclatura química, ele trouxe a contextualização dos conceitos. Essa contextualização transportava a química para a realidade do discente, envolvendo o conhecimento prévio da química na vida de todos os alunos participantes.

Desta forma, no processo da compreensão das regras do jogo Ouroboros, é possível também questionar outros conteúdos. Não havendo necessidade alguma do conteúdo se tornar um martírio para o aluno. Sugere o autor Nunez:

(...) que haja a (re) significação dos conteúdos curriculares como meio para a constituição de competências e valores, e não como objetivos do ensino em si mesmos e que se adote estratégias de ensino diversificadas, de modo a buscar a utilização mais do raciocínio e menos da memória (NUNEZ, 2002, p.77).

$\mathrm{O}$ aluno precisa passar pela escola para construir conhecimento e boas experiências e, com essa temática, torna-se possível desenvolver o conteúdo utilizando o jogo Ouroboros, que ajudará este aluno a aprender de uma forma mais descontraída. Após a aplicação do jogo, os alunos terão a oportunidade de aprofundar seus conhecimentos ou até mesmo adquiri-los, e seu rendimento escolar poderá aumentar significativamente. A partir desta reflexão sobre o jogo, permite-se esclarecer que cada professor conheça as razões da opção por determinado conjunto de atividades, quais são as competências que se busca desenvolver com elas e que prioridades norteiam o uso dos recursos materiais e a distribuição das questões no tabuleiro.

O jogo Ouroboros permite, sobretudo, que o graduando compreenda o sentido e a relevância desse trabalho em sua disciplina para que as metas formativas gerais definidas para os alunos da escola sejam atingidas através da inovação pedagógica (SILVA et all., 2017). Sendo assim, a utilização de jogos didáticos em sala de aula tem se apresentado benéfica, de modo que há uma aproximação dos alunos, ocorre um diálogo sobre o conteúdo, estimulando o saber através da curiosidade de forma prazerosa, mesmo tendo um rigor metodológico onde se objetiva a construção do saber (SOARES, 2015).

Conforme os Parâmetros Curriculares Nacionais para Ciências da Natureza (BRASIL, 2014, p.9), “A transformação de qualidade que se procura promover na formação dos jovens irá conviver com mudanças quantitativas e qualitativas, decorrentes de processos sociais e culturais mais amplos, que precisam ser consideradas e compreendidas". O autor ainda argumenta:

Recebido em: 24/03/2020

Aceito em: 20/07/2020 


\begin{abstract}
Adequar à escola a seu público atual é torná-la capaz de promover a realização pessoal, a qualificação para um trabalho digno, para a participação social e política, enfim, para uma cidadania plena da totalidade de seus alunos e alunas. Isso indica a necessidade de revisão do projeto pedagógico de muitas escolas que não se renovam há décadas, criadas em outras circunstâncias, para um outro público e para um mundo diferente deste dos nossos dias. É preciso identificar os pontos de partida para se construir essa nova escola, e reconhecer os obstáculos que dificultam sua implementação, para aprender a contorná-los ou para superá-los (BRASIL, 2014, p.9).
\end{abstract}

Como foi registrado anteriormente, o futuro Profissional de Química deve possuir conhecimento químico e necessita ser um meio "de interpretar o mundo e intervir na realidade, além de desenvolver capacidades como interpretação e análise de dados, argumentação, conclusão, avaliação e tomadas de decisões". (CASTILHO et all., 1999; BRASIL, 1999).

No entanto, ao jogar os alunos terão a oportunidade de aprofundar os seus conhecimentos de química ou até mesmo adquiri-los e seu rendimento escolar poderá aumentar significativamente. A pesquisa de campo possibilitou observar a riqueza dos benefícios que a utilização de jogos no ensino de química traz aos alunos, e aos professores que usam essa metodologia, a satisfação de proporcionar a ludicidade aos educandos.

Percebeu-se também que o conhecimento pode ser potencializado de forma significativa aplicando uma prova antes da realização do jogo. A avaliação aplicada novamente depois do jogo demonstra a melhora nas notas, refletindo o sucesso do aprendizado adquirido de uma forma diferente, divertida e acessível (considerando os resultados positivos dos alunos com maior dificuldade). É possível verificar tudo o que foi apresentado até o momento no gráfico 1, que explicita a porcentagem de acertos dos alunos no pré-teste que foi aplicado na turma. Foi possível observar que algumas questões apresentaram baixa porcentagem de acertos principalmente a partir da sétima questão. 
Vol. 3, n. 5. Set./Dez.

ISSN: 2595- 4520

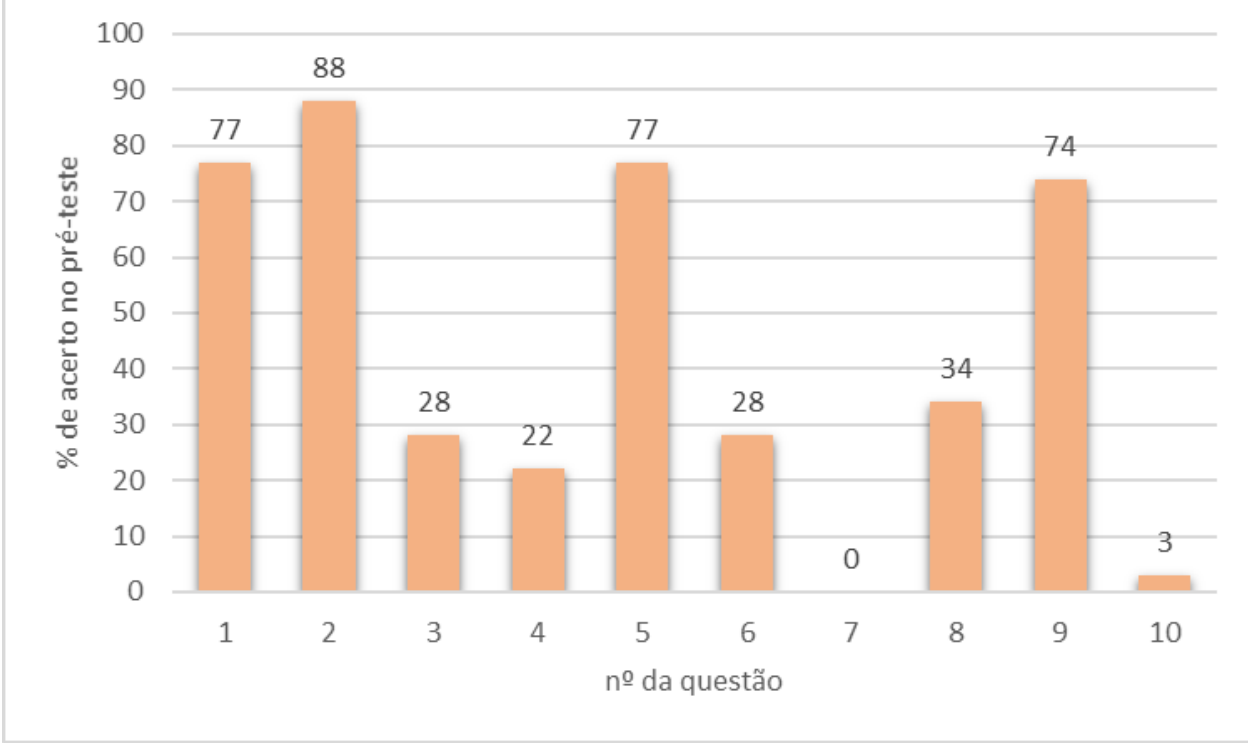

Gráfico 1- Porcentagem de acertos no pré-teste Ouroboros.

No segundo teste, pós-jogo, que reunia as questões anteriores com menor número de acertos, incluídas de forma aleatória entre um total de dez questões, os alunos conseguiram aumentar seu rendimento. Através do gráfico 2 é possível observar que houve uma significativa melhora nos acertos. A questão de número 7 no pré-teste, que ninguém havia respondido, depois do jogo Ouroboros teve $41 \%$ de acerto. A questão de número 10 , que apresentou muita dificuldade no pré-teste, obteve $64 \%$ de acerto. Lembrando que as questões de 1 a 6 foram objetivas e as de 7 a 10 são questões discursivas. Percebemos que as questões discursivas tiveram o menor número de acertos, e depois da atividade, apresentaram melhores resultados. Inclusive a questão 7 , que nenhum discente havia respondido de forma correta, apresentou $41 \%$ de acerto na nova avaliação. 


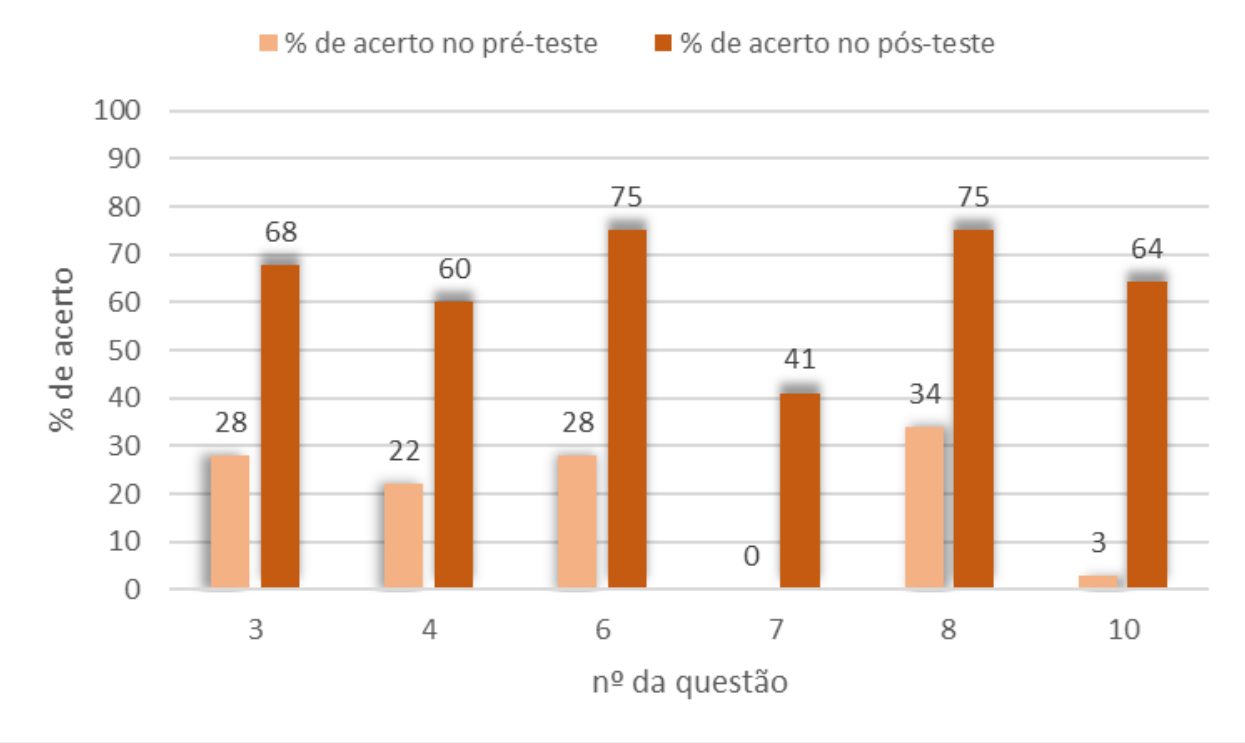

Gráfico 2 - Porcentagem de acerto no Pré-teste versus Pós-teste Ouroboros.

Como colocado anteriormente, a possibilidade de um jogo melhorar o interesse dos alunos nas aulas de química, por estimular a reflexão e a troca de saberes, é bastante tangível. Este trabalho propiciou a constatação deste fato, pois os alunos, além de participarem de uma atividade lúdica, puderam se divertir e criar estratégias para vencer. Apresentaram também uma melhora significativa em seu aprendizado, que foi comprovado através dos testes aplicados antes e depois de jogarem o Ouroboros. Apesar de muitas vezes o professor procurar outras práticas para que seu aluno tenha sucesso em sua disciplina e consiga notas satisfatórias, talvez seu objetivo não seja alcançado se não houver uma abordagem metodológica e pedagógica, pois concordamos com Starepravo (1999, p.15) quando afirma que "os jogos não proporcionam "grandes milagres", a produtividade do trabalho depende diretamente do encaminhamento dado pelo Professor". Antunes (2008) afirma que os jogos pedagógicos devem ser usados com bastante cautela com um bom planejamento de aula, na qual se respeite e acompanhe o progresso dos alunos. Ressaltamos que o jogo pedagógico não deve substituir a aula do professor e sim complementar sua prática, atingindo um maior número de alunos no processo de ensino e aprendizagem.

Sobre o comportamento da turma, foi nítido o clima de euforia, competitividade, entusiasmo e vontade de vencer. Cada grupo de esforçou para derrotar o outro, para isso usaram estratégias, raciocínio rápido para que pudessem se dar bem nessa atividade, vibravam muito a cada questão que conseguiam acertar. $O$ interessante na interação dos alunos foi a discussão das respostas das questões presentes nas cartas, 
cada um contribuindo de forma objetiva para construir a reposta certa. Em muitas das jogadas os discentes buscavam em seus pares o conhecimento prévio da química para responder as questões. Os discentes ficavam eufóricos quando a equipe oposta perdia seu turno, podendo assim ganhar vantagem no percurso. Acreditamos que a melhora na porcentagem de acerto das questões se deva à interação entre os alunos, uma vez que o pré-teste e o pós-teste foram individuais. Essa interação e socialização dos conhecimentos individuais em um grupo pode ter contribuído para que os discentes construíssem individualmente a resposta correta da questão 7 no pós-teste, a qual ninguém respondeu corretamente no pré-teste.

Ao observar a turma, é possível dizer que jogar traz de volta a criança que existe dentro dos jovens e adultos, pois a fantasia e a realidade interagem na produção de novas formas de interpretação, de expressão, onde eles são integrados com os outros, consigo mesmo e com o meio social, além de estarem adquirindo conceitos, aprendendo através das questões que precisavam resolver para ter sucesso na situação em que foram colocados. Os professores não devem olhar o jogo apenas como brincadeira, pois os alunos o levam muito a sério buscando a vitória.

O jogo de tabuleiro Ouroboros é um jogo relevante, que estimula várias discussões no contexto do ensino de ciências. A construção do conhecimento pelo aprendiz não é um processo linear, é complexo, tortuoso, demorado, com avanços e retrocessos, continuidades e rupturas (MOREIRA, 2009). No entanto, a aprendizagem se torna mais fácil quando se torna mais prazerosa a forma de se aprender (DARRÓZ et all., 2007). Ouroboros trata-se de uma nova versão reinventada a partir do conhecimento do jogo de tabuleiro para ser aplicada nas turmas de graduação, a fim de verificar se há a viabilidade de jogos didáticos recriados auxiliarem efetivamente no processo de aprendizagem dos futuros profissionais de educação de Química. Além disso, é possível, observar a crescente curiosidade dos alunos a respeito de jogos e brincadeiras, e a valorização crescente em nosso país pela potencialidade dos jogos no ensino de Ciências da Natureza. Entendemos que a atividade do jogo Ouroboros tenha contribuído para o aprendizado, da mesma forma como uma roda de conversa sobre um livro ou filme. Esse tipo de atividade leva aos discentes o conhecimento de uma forma descontraída e prazerosa, lembrando do que foi discutido durante o jogo, da mesma forma que lembram do enredo de um filme ou de um livro. 
Esse jogo dá a viabilidade por meio da metodologia lúdica de oferecer a oportunidade ao graduando de refletir sobre o conteúdo. Propicia a participação do estudante, ou mesmo do futuro professor, na execução da tarefa dos jogos, no tabuleiro, estimulando o mesmo a dar mais atenção às disciplinas pedagógicas. Por meio do jogo OuroBoros propiciam-se perspectivas do graduando para melhorar o aprendizado e ser um profissional de Educação mais atuante e bem-sucedido na sociedade.

\section{CONSIDERAÇÕES FINAIS}

Nos dias atuais, os professores buscam alternativas diferenciadas para potencializar os processos de ensino-aprendizagem. Muitas metodologias de ensino inovadoras são instrumentos cada vez mais comuns no cotidiano educacional. Por isso, é muito válida a utilização de jogos, eletrônicos ou convencionais, como ferramentas eficientes no auxílio da aprendizagem, inclusive para despertar a interação social entre os alunos.

A pesquisa-ação possibilitou observar a riqueza dos benefícios que o emprego de jogos no ensino de ciências traz aos alunos e professores que usam essa metodologia. Verifica-se que mesmo aqueles alunos com maior dificuldade poderão ter a chance de melhoria da qualidade de ensino diante de suas dificuldades, ou seja, a aquisição do conhecimento é um dos benefícios que o jogo didático pode proporcionar. $\mathrm{O}$ jogo de tabuleiro Ouroboros é um jogo significativo, que faz com que surjam discussões importantes no contexto sobre o ensino de ciências, visto que a construção do conhecimento pelo aluno não é um processo muito fácil.

Após a realização do pós-teste, foi possível verificar que realmente o jogo Ouroboros ajuda muito o graduando a aprender com eficiência e exatidão conteúdos de forma lúdica e descontraída. Foi nítida também a motivação da turma em relação ao jogo, e o interesse em resolver as questões para vencer.

O trabalho desenvolvido possibilitou a motivação e melhora no rendimento do aluno, além da socialização que o prepara para inúmeras situações da vida. Por esse motivo, espera-se que a utilização de jogos didáticos em sala de aula seja inserida nas práticas educativas para formar alunos reflexivos, autônomos, criativos e não meros reprodutores de conceitos.

\section{Agradecimentos:}

Recebido em: 24/03/2020

Aceito em: 20/07/2020 
Os autores gostariam de agradecer à Margareth Drebes da MD Dragons pelas ilustrações do tabuleiro e das cartas. O presente trabalho foi realizado com apoio da Coordenação de Aperfeiçoamento de Pessoal de Nível Superior - Brasil (CAPES).

\section{REFERÊNCIAS:}

ADVERSE, A. O. (2019). Absolutamente outro [Dandismo \& Melancolia]. Palíndromo, v. 11, n. 24, p. 99-117. Acessado em: 19 ago,2019, http://periodicos.udesc.br/index.php/palindromo/article/view/12541/10130.

ALMEIDA, A. (2009). A ludicidade como instrumento pedagógico. Acesso em 26 jun, 2015, http//www.cdof.com.br/recrea.22.htm.

ANTUNES, C.(2008). O jogo e a Educação: falar e dizer/ olhar e ver/ escutar e ouvir. $6^{\circ}$ Ed. Petrópolis, RJ. Vozes.

BENEDETTI FILHO, E.; CAVAGIS, A.; LIMA, M.; BENEDETTI, L. Fuga! Um jogo de tabuleiro desenvolvido para a revisão de conceitos de Química. Revista Insignare Scientia - RIS, v. 3, n. 1, p. 77-95, 4 jun. 2020

BRASIL. (2014). Parâmetros Nacionais Curriculares: Ciências da Natureza e Matemática e suas Tecnologias. Acesso 20 jul, 2019, http://portal.mec.gov.br/seb/arquivos/pdf/CienciasNatureza.pdf.

BRUNER, J. (1969). Uma nova teoria de aprendizagem. Rio de Janeiro: Bloch Editores.

CAILLOIS, R.(1975). The game as word symbol. Critique, 31(342).

CAMPANARIO, in J.M., S MOYA, A. (1999). ¿Como enseñarciencias?principalestendencia y propuestas.Enseñanza de las Ciencias, 17 (2), 179-192. Acesso 01 ago, 2019, https://scholar.googleusercontent.com/scholar?q=cache:_YLHv5AtvwJ:scholar.google. com/+Campanario,+J.M.+y+Moya,+A.+(2001).+\%C2\%BFComo+ense\%C3\%B1ar+cie ncias $\% 3$ Fprincipales+tendencias+y+propuestas.Ense $\% \mathrm{C} 3 \% \mathrm{~B} 1$ anza+de+1\%C3\% $33 \mathrm{~s}+\mathrm{Ci}$ encias $,+17+(2),+179-192 \&$ hl=pt-BR\&as_sdt=0,5.

CASTILHO, D.L., SILVEIRA, K.P. ; MACHADO, A.H. (1999). As aulas de Química como espaço de investigação e reflexão. Química Nova na Escola, 9, 14-17. Acesso 05 jul,

2019 ,

http://webeduc.mec.gov.br/portaldoprofessor/quimica/sbq/QNEsc09/relatos.pdf.

CORRÊA, T. H. B. SCHNETZLER, R. P. (2017). Da formação à atuação: obstáculos do tornar-se professor de Química. Revista Debates em Ensino de Química, v. 3, n. 1, p. 28-46.Acesso 19 ago, 2019, http://www.journals.ufrpe.br/index.php/REDEQUIM/article/view/1356 .

CHATEAU, J. (1984). O jogo e a criança. São Paulo: Summus Editora.

Recebido em: 24/03/2020

Aceito em: 20/07/2020 
CUNHA, Marcia Borin.(2012) Jogos no ensino de química: considerações teóricas para sua utilização em sala de aula. Química Nova na Escola, São Paulo, [s. L.], v. 34, n. 2, p. 92-98. Aceso em 19 de ago, 2019, http://qnesc.sbq.org.br/online/qnesc34_2/07-PE53-11.pdf.

DEUS, Thiago Cardoso de; SOARES, Márlon Herbert Flora Barbosa. O JOGO DE REALIDADE ALTERNADA CURTO (SHORT ARG) COMO ESTRATÉGIA DE DISCUSSÃO DE CONCEITOS QUÍMICOS EM NÍVEL SUPERIOR. Quím. Nova, São Paulo , v. 43, n. 3, p. 362-370, Mar. 2020 . Available from <http://www.scielo.br/scielo.php?script=sci_arttext\&pid=S0100-

40422020000300362\&lng=en\&nrm=iso>. access on 09 June 2020. Epub June 01, 2020. https://doi.org/10.21577/0100-4042.20170479.

SILVA, C. M. de J.; ALMEIDA, H. C. R. de; NETO J. E. S. \& SILVA, J. da C. S. da (2017). Percepção dos licenciandos em química sobre a aplicação do jogo da química II. Revista Eletrônica Ludus Scientiae, v. 1, n. 1,. Acesso 18 ago 2019, https://revistas.unila.edu.br/relus/article/view/788/725.

SILVA, E. de A. N.; JESUS, C. P. F. de; MENDES, A. N. F. \& ROCHA, S.M.S. (2019). Jogando com a química: um instrumento de aprendizagem no ensino da eletroquímica. Revista de Estudos e Pesquisas sobre Ensino Tecnológico (EDUCITEC), $\begin{array}{lllllll}\text { v. } & 5, & \text { n. } & 10 . & \text { Acesso } & 20 & \text { ago, }\end{array}$ http://200.129.168.14:9000/educitec/index.php/teste/article/view/434/257.

DARRÓZ, A. L.; OLIVEIRA, C. de.; CHAVE, M. (2007). As Diversas Interfaces do Lúdico Na Aprendizagem. Maringá PR.

ESCREMIN, J.V.; CALEF, P.S (2018). Jogos, ensino e formação de professores reflexivos. $1^{\text {a }}$ Ed. Curitiba, PR. Editora Appris.

FORTUNA, T.R. (2000). Sala de aula é lugar de brincar? In: Xavier, M.L; Dallazen, M.I. H.(org.). Planejamento em destaque: analises menos convencionais: Porto Alegre: Mediação, 2000. (Caderno de Educação Básica, 6) p. 146- 164. Acesso 10 ago, 2019, http://www.andreaserpauff.com.br/arquivos/disciplinas/brinquedosebrincadeiras/6.pdf.

GALLIAZZI, M.C., ROCHA, J.M.B., SCHMITZ, M.L.S., GIESTA, S., GONÇALVES, F.P. (2001). Objetivos das atividades experimentais no ensino médio: a pesquisa coletiva como formação de professores de ciências. Ciência e educação, 7(2), 249-263. Acesso 12

ago, 2019,http://www.scielo.br/scielo.php?pid=S151673132001000200008\&script=sci_artte xt\&tlng=es.

GIL-PEREZ, D. (1993). Contribuición de la Historia y de la filosofía de lasCiencias al desarollo de un modelo de enseñanza e aprendizaje como investigación. Enseñanza de las Ciencias, 11 (2), 197-212. Acesso 12 ago, 2019, https://www.raco.cat/index.php/ensenanza/article/viewFile/21204/93254.

HARTMANN, A. C.; MARONN, T. G.; SANTOS, E. G. (2019). A importância da aula expositiva dialogada no ensino de ciências e biologia. II Encontro de Debates sobre

Recebido em: 24/03/2020

Aceito em: 20/07/2020 
Trabalho, Educação e Currículo Integrado, v. 1, n. 1. Acesso 19 ago 2019,https://publicacoeseventos.unijui.edu.br/index.php/enteci/article/view/11554/1024.

HENRIOT, J. (1967). Problems with research in educational Psychology. Psychology, 20 (190).

HUINZIGA, J. (1980). Homo Ludens: O jogo como elemento de cultura. São Paulo: Editora Perspectiva.

KISHIMOTO, T.M. (1996). Jogo, brinquedo, brincadeira e a educação. São Paulo: Cortez.

LAPA, W. de P. F. M.; SILVA, J. da C. S. da. (2018). Jogos no ensino de química: Fundamentos e aplicações. Editora CRV. Curitiba-PR.

MEDEIROS, C.E., RODRIGUEZ, R. de C.M.C.; SILVEIRA, D.N. (2016) Ensino de Química: superando obstáculos epistemológicos. $1^{\circ}$ Ed. Curitiba-PR. Editora Appris.

MELO, C.M.R. (2005). As atividades lúdicas são fundamentais para subsidiar ao processo de construção do conhecimento. Informação Filosófica, 2(1), 128-137.

MOREIRA, M.A (2009). A teoria dos campos conceituais, o ensino de ciências e a pesquisa nesta área.

NUNEZ, C. (2002). Ensino Médio. Rio de Janeiro: DP\&A.

PEREIRA, F. S. F. (2017). Uso de jogos educativos como aliado no processo de ensino aprendizagem de química. Revista de Pesquisa Interdisciplinar, [S.1.], v. 1, fev. ISSN 2526-3560.Acesso $19 \quad$ ago, 2019 , http://revistas.ufcg.edu.br/cfp/index.php/pesquisainterdisciplinar/article/view/114/94.

PIAGET, J. (1975). A formação do símbolo na criança: Imitação, Jogo, Sonho, Imagem e Representação. Rio de Janeiro: Editora Zohar.

REZENDE, F. A.M.; CARVALHO, C. V. M.; GONTIJO, L. C.; SOARES, M. H. F. B. (2018). RAIO QUIZ: Discussão de Um Conceito de Propriedade Periódica por Meio de Um Jogo Educativo. Acesso 15 ago, 2019, http://qnesc.sbq.org.br/online/artigos/RSA19-18.pdf

ROCHA, J. S.; VASCONCELOS, T. C. (2016). Dificuldades de aprendizagem no ensino de química: algumas reflexões. XVIII Encontro Nacional de Ensino de Química (XVIII ENEQ), p. 1-10. Acesso 19 ago, 2019, http://www.eneq2016.ufsc.br/anais/resumos/R0145-2.pdf.

SANTOS, S. M. dos. (2018). Jogos no ensino de química: uma breve análise de trabalhos apresentados por discentes do curso de Licenciatura em Química da UFRB. $\begin{array}{llll}\text { Acesso } & 19 & \text { ago, 2019, }\end{array}$ http://www.repositoriodigital.ufrb.edu.br/bitstream/123456789/1372/1/TCC\%20FINAL \%20Samuel.pdf. 
SOARES, M. H. F. B. (2015). Jogos e Atividades lúdicas para o ensino de Química. 2a Ed. Goiania- GO. Editora Kelps.

SOUSA, M. D. P. de (2012). Mandalas ou o círculo mágico: uma abordagem em contexto educativo. Tese de Doutorado. Acesso 19 ago, 2019, https://repositorio.ul.pt/handle/10451/9929.

TEIXEIRA, V. M. M. de L.; Dos SANTOS, A. R.; GRAEBNER, I. B. (2019). O docente de química e a busca do fazer diferente: um estudo sobre as formas alternativas para ensinar. Scientia Naturalis, v. 1, n. 3. Acesso 18 ago, 2019, https://periodicos.ufac.br/index.php/SciNat/article/view/2565/1471.

VYGOTSKY, L.S. (1989). A formação social da mente. São Paulo: Martins Fontes.

STAREPRAVO, A.R. (1999). O jogo e a Matemática no ensino Fundamental. Curitiba: Renascer.

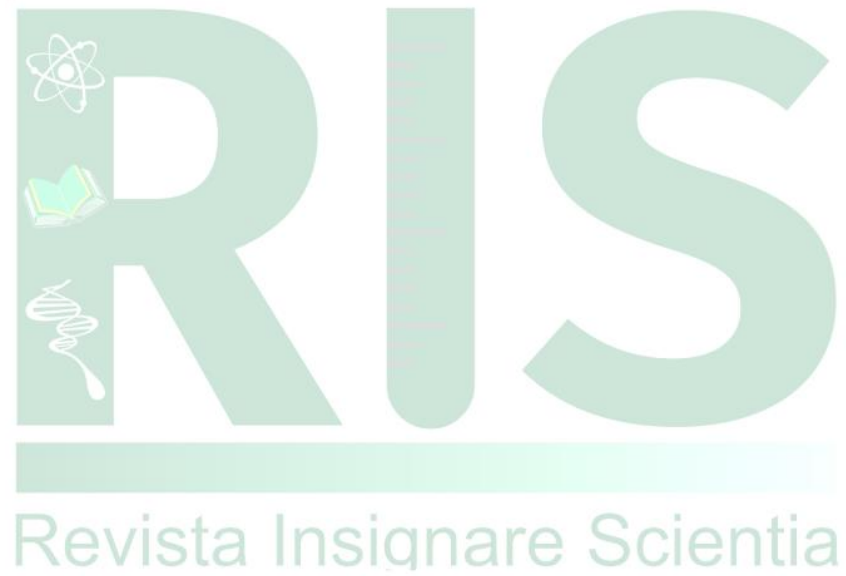

